\title{
Numerical Study on the Extrapolation Method for Predicting the Full-scale Resistance of a Ship with an Air Lubrication System
}

\author{
Dong-Young Kim ${ }^{1}$, Ji-Yeon Ha®1 and Kwang-Jun Paik ${ }^{2}$ \\ ${ }^{1}$ Graduate Student, Department of Naval Architecture and Ocean Engineering, Inha University, Incheon, South Korea \\ ${ }^{2}$ Associate Professor, Department of Naval Architecture and Ocean Engineering, Inha University, Incheon, South Korea
}

KEY WORDS: Air lubrication system, Full-scale resistance, Frictional resistance, Form resistance, CFD

\begin{abstract}
Frictional resistance comprises more than $60 \%$ of the total resistance for most merchant ships. Active and passive devices have been used to reduce frictional resistance, but the most effective and practical device is an air lubrication system. Such systems have been applied in several ships, and their effects have been verified in sea trials. On the other hand, there are some differences between the results predicted in model tests and those measured in sea trials. In this study, numerical analyses were carried out for a model and a full-scale ship. A new extrapolation method was proposed to improve the estimation of the full-scale resistance of a ship with an air lubrication system. The volume of fluid (VOF) method was considered for the numerical models of the air layer. The numerical method was validated by comparing the experimental data on the air layer pattern and the total resistance.
\end{abstract}

\section{Nomenclature}

$\begin{array}{ll}S L P M & \text { Standard liter per minute }(\mathrm{L} / \mathrm{min}) \\ t_{A L} & \text { Air layer thickness }(\mathrm{mm}) \\ Q_{\text {Air }} & \text { Volume flow rate of air }\left(\mathrm{m}^{3} / \mathrm{s}\right) \\ B_{\text {Air }} & \text { Width of the air injection slit }(\mathrm{m}) \\ V_{\text {Inflow }} & \text { Inflow speed of water }(\mathrm{m} / \mathrm{s})\end{array}$

\section{Introduction}

The International Maritime Organization (IMO) has mandated a $30 \%$ reduction in $\mathrm{CO}_{2}$ emissions by 2025 for ships, which produce $3.3 \%$ of global $\mathrm{CO}_{2}$ emissions. To reduce $\mathrm{CO}_{2}$ emissions, it is essential to estimate the ship's resistance and propulsion accurately and improve performance.

Frictional resistance generally accounts for more than $60 \%$ of the total resistance of a ship. An air lubrication system injects air onto the hull surface to form a continuous air layer, reducing frictional resistance on the hull surface and fuel consumption (Bushnell and Hefner, 1990; Ceccio, 2010). The frictional resistance can be reduced in three ways: bubble drag reduction (BDR), air layer drag reduction (ALDR), and partial cavity drag reduction (PCDR). PCDR can increase the form resistance due to remodeling of the air cavity, but it is difficult to apply to a ship. Compared to BDR, ALDR requires high pumping power, but the resistance reduction rate is very high (Ceccio et al., 2012).

Jang et al. (2014) observed air layer formation using ALDR in the lower part of a plate in the cavitation tunnel of the Samsung Ship Model Basin (SSMB). They also measured the decrease in frictional resistance. An air layer was applied to a model 66K DWT Supramax bulk carrier to estimate the power-saving effect by conducting resistance and self-propulsion tests

Mäkiharju et al. (2017) examined the gas pocket morphology with air injection at a single inlet. The formation of a $\mathrm{V}$-type gas pocket and the shape of the gas pocket were observed while changing the inflow rate and air injection rate. Computational fluid dynamics (CFD) simulations and experimental results showed similar tendencies.

Kim et al. (2017) analyzed the air layer pattern and diffusion angle at the bottom of a plate numerically using CFD. The air diffusion angle pattern according to the relationship between the air inflow rate and water inflow velocity was compared with the empirical formulae. They compared the lambda, delta, and transition air-layer patterns through the velocity vectors, velocity contours, and vorticity contours. On the other hand, the practical application of ALDR required multiple

Received 11 February 2020, revised 12 October 2020, accepted 19 October 2020

Corresponding author Kwang-Jun Paik: +82-32-860-7331, kwangjun.paik@inha.ac.kr

(c) 2020, The Korean Society of Ocean Engineers

This is an open access article distributed under the terms of the creative commons attribution non-commercial license (http://creativecommons.org/licenses/by-nc/4.0) which permits unrestricted non-commercial use, distribution, and reproduction in any medium, provided the original work is properly cited. 
complex injections rather than a single injection.

Mäkiharju and Ceccio (2018) observed the shape changes of airflow with complex interactions in a multi-injection experiment. In some cases, multiple injections formed a more stable air layer than a single injection because each of the air layers interacted with each other. Multiple injections generated a larger gas pocket that formed into a liquid cross-flow, but a fortuitous gas pocket formed in some cases. Therefore, additional experiments are needed. In addition, it is necessary to cover a large number of flow parameters and derive clear results through further experiments using models with greater overall lengths.

Estimating the resistance reduction effects of an air lubrication system on a full-scale ship is important before studying the influence of the position, shape, and number of injectors. A more accurate method is also needed to estimate the full-scale ship resistance from the resistance components of a model ship.

The goal of this study was to improve the estimation of the actual resistance of air lubricated ships. A numerical method was developed and verified by comparing with experimental data (Jang et al., 2014). A new extrapolation method was proposed to estimate the full-scale resistance of a ship with an air lubrication system based on the numerical simulations for a model and full-scale ship.

\section{Numerical Methods and Models}

Incompressible three-dimensional unsteady flow was modeled to analyze the air lubrication performance. The continuity equation and Reynolds averaged Navier-Stokes (RANS) equations were used as the governing equations.

$$
\begin{aligned}
& \frac{d}{d t} \int_{V} \rho d V+\int_{S} \rho u_{i} n_{i} d S=0 \\
& \frac{d}{d t} \int_{V} \rho u_{i} d V+\int_{S} \rho u_{i} u_{j} n_{j} d S \\
& \quad=\int_{S}\left(\tau_{i j} n_{j}-\rho n_{i}\right) d S+\int_{V} \rho b_{i} d V
\end{aligned}
$$

where $u_{i}$ is the velocity tensor, and $b_{i}$ is the tensor of body forces. $p$ and $\rho$ are the pressure and density, respectively. $\tau_{i j}$ is the effective stress of the viscosity and turbulence:

$$
\tau_{i j}=\mu_{e}\left[\left(\frac{\partial u_{i}}{\partial x_{j}}+\frac{\partial u_{j}}{\partial x_{i}}\right)-\frac{2}{3} \delta_{i j} \frac{\partial u_{k}}{\partial x_{k}}\right]
$$

where $\mu_{e}$ is the effective dynamic viscosity.

The commercial CFD software, STAR-CCM + 12.06, was used for numerical analysis of multiphase flow. The volume of fluid (VOF) method was used for multiphase flow replication, considering the free surface and air layer. The Reynolds stress model (RSM) was used as the turbulence model. Table 1 lists the numerical models.
Table 1 Numerical models

\begin{tabular}{cc}
\hline Tool & STAR-CCM+ ver.12.06 \\
Turbulence model & Reynolds stress model \\
Time & Implicit unsteady \\
Multiphase & Volume of fluid (VOF) \\
Diffusion term & $2^{\text {nd }}$ order central difference scheme \\
Convection term & $2^{\text {nd }}$ order upwind difference scheme \\
\hline
\end{tabular}

\section{Setup of the Numerical Simulation}

A scale model of a 66K DWT Supramax bulk carrier was used in the model test by Jang et al. (2014). Table 2 lists the main specifications of the ship. The model ship was scaled at a factor of 24.0. Therefore, the same factor was applied in numerical analysis.

Table 2 Specifications of the 66K DWT Supramax bulk carrier.

\begin{tabular}{cc}
\hline \multicolumn{2}{c}{ Specifications } \\
\hline Length overall & $200.0 \mathrm{~m}$ \\
Length between perpendicular & $192.0 \mathrm{~m}$ \\
Breadth & $36.0 \mathrm{~m}$ \\
Draft & $11.2 \mathrm{~m}$ \\
Displacement volume & $65,012.3 \mathrm{~m}^{3}$ \\
Wetted surface area & $9,909.6 \mathrm{~m}^{2}$ \\
$C_{B}$ & 0.840 \\
\hline
\end{tabular}

\subsection{Computational Domain and Boundary Conditions}

Fig. 1 shows the boundary conditions and the computational domain. A Cartesian coordinate system was used. Based on the center of gravity of the hull, the $\mathrm{x}$-axis was set as the direction from the stern to the bow; the $y$-axis was set as the portside direction, and the z-axis was set as the opposite direction of gravity. The boundary conditions of the inlet surface, top surface, and bottom surface were set as the velocity inlet, and the outlet surface was set as the pressure outlet.

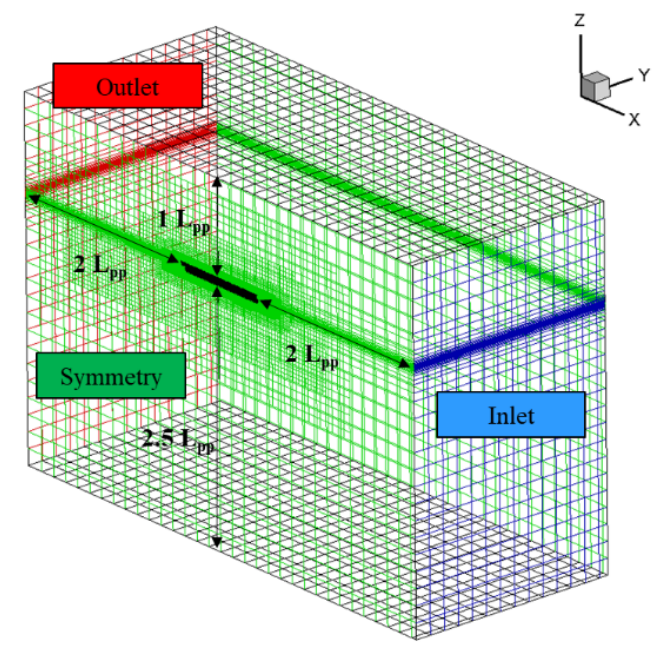

Fig. 1 Boundary conditions and grid system 
Symmetric conditions were applied across the y-axis interface because the hull is perfectly symmetrical. Symmetric conditions were applied to the side to reduce the distortion of the reflected wave. The distances from the bow to the inlet, the hull to the top, the hull to the bottom, and the stern to the outlet were $2 L_{p p}, 1 L_{p p}, 2.5 L_{p p}$, and $2 L_{p p}$, respectively.

\subsection{Injector Geometry}

In the model test by Jang et al. (2014), the injector shapes were made with many holes, but they were modeled as a single slit in numerical analysis. Figs. 2 and 3 present the diagrams of the air cavity and the geometry of the air injector. The width and length of the slit were 6 $\mathrm{mm}$ and $260 \mathrm{~mm}$, respectively. The air injection slits, $\mathrm{C} 1$ and $\mathrm{C} 2$, were located at the $17^{\text {th }}$ and $15^{\text {th }}$, respectively.

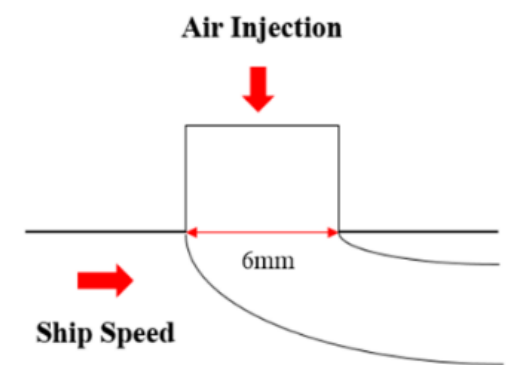

Fig. 2 Diagram of the air injector

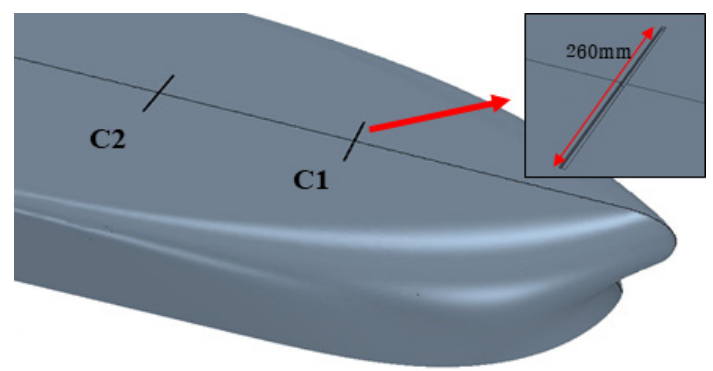

Fig. 3 Geometry of air injector

\subsection{Grid Test}

The grid system was verified by measuring the resistance according to the number of grid elements (approximately 1.0 million, 2.5 million, and 6.1 million). Differences of $0.118,0.092$, and $0.013 \%$ were observed compared with the model test results performed at SSMB in Fig. 4. The simulation took too much time when there were 6.1 million grid elements. When there were 1.0 million grid elements, realistic phenomena could not be observed when air was injected. Therefore, the medium grid size of 2.5 million was applied for the other simulations.

Table 3 lists the reduction ratio of the resistance due to the air layer under various combinations of the air injection flow rate and injection position. The ship speed was fixed to $1.5226 \mathrm{~m} / \mathrm{s}$, which corresponds to the design speed of 14.5 knots for a full-scale ship using Froude scaling. The total amount of air injected from $\mathrm{C} 1$ and $\mathrm{C} 2$ was set to a wide range of 0 to 400 liters per minute under standard conditions of 1 atm and $25^{\circ} \mathrm{C}(\mathrm{SLPM})$, as shown in Table 3.

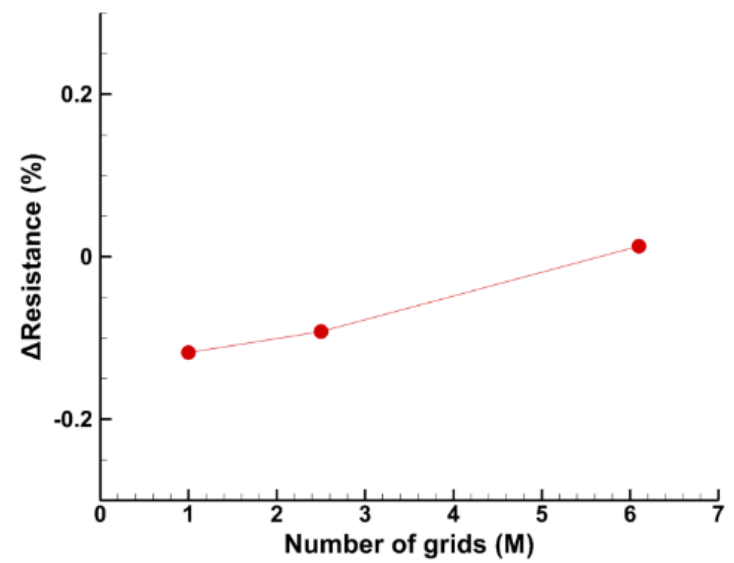

Fig. 4 Gird verification for the number of grids

Table 3 Simulation cases

\begin{tabular}{cccc}
\hline Case & Injection position & $S L P M$ & $t_{A L}(\mathrm{~mm})$ \\
\hline Bare & - & 0 & 0 \\
Case 1 & $\mathrm{C} 1$ & 50 & 2.1 \\
Case 2 & $\mathrm{C} 1$ & 100 & 4.2 \\
Case 3 & $\mathrm{C} 1$ & 150 & 6.3 \\
Case 4 & $\mathrm{C} 2$ & 100 & 4.2 \\
Case 5 & $\mathrm{C} 2$ & 150 & 6.3 \\
Case 6 & $\mathrm{C} 2$ & 250 & 10.5 \\
Case 7 & $\mathrm{C} 1 / \mathrm{C} 2$ & $100 / 200$ & $4.1 / 8.4$ \\
Case 8 & $\mathrm{C} 1 / \mathrm{C} 2$ & $100 / 250$ & $4.1 / 10.6$ \\
Case 9 & $\mathrm{C} 1 / \mathrm{C} 2$ & $100 / 300$ & $4.1 / 12.7$ \\
\hline
\end{tabular}

Eq. (4) was used to estimate the air layer thickness:

$$
t_{A L}=\frac{Q_{\text {Air }}}{B_{\text {Air }} \cdot V_{\text {Inflow }}}
$$

where $Q_{A i r}, B_{\text {Air }}$, and $V_{\text {Inflow }}$ are the volume flow rate of the injected air, the width of the air injection slit, and the inflow speed, respectively.

\section{Results and Discussion}

\subsection{Reduction in Resistance}

Table 4 presents the trim and sinkage of the ship that occurred when air was injected. A positive value occurs when the ship rises to the top, and the bow is trimmed. The largest change in trim ( $\Delta$ Trim) was $4.1 \%$ in Case 5. The ship was tilted more toward the bow by the buoyancy of air flowing from the bottom to the stern. On the other hand, the change in trim is not proportional to the amount of air. The change in sinkage ( $\triangle$ Sinkage) also increased continuously due to buoyancy as the amount of air injection increased.

Table 5 shows the total resistance reduction of the model ship ( $\Delta$ $R_{T M}$ ), the ratio of the decrease in shear resistance to the decrease in total resistance $\left(\Delta R_{\text {Shear }}\right)$, and the ratio of the decrease in pressure resistance to the decrease in total resistance $\left(\Delta R_{\text {Pressure }}\right)$. The largest 
Table 4 Reduction rate of the trim and sinkage under each air injection condition

\begin{tabular}{cccc}
\hline Case & $\Delta R_{T M}(\%)$ & $\Delta$ Trim $(\%)$ & $\Delta$ Sinkage $(\%)$ \\
\hline Bare & - & - & - \\
Case 1 & 11.2 & 1.0 & 2.7 \\
Case 2 & 15.0 & 1.8 & 6.0 \\
Case 3 & 17.5 & 0.0 & 8.7 \\
Case 4 & 14.3 & 3.3 & 5.0 \\
Case 5 & 16.8 & 4.1 & 7.3 \\
Case 6 & 21.0 & 3.4 & 11.2 \\
Case 7 & 23.3 & 2.1 & 13.4 \\
Case 8 & 24.9 & 1.6 & 15.5 \\
Case 9 & 26.1 & 2.5 & 16.5 \\
\hline
\end{tabular}

Table 5 Resistance and reduction rate of the resistance component under each air injection condition

\begin{tabular}{cccc}
\hline Case & $\Delta R_{T M}(\mathrm{~N})$ & $\Delta R_{\text {Shear }}(\%)$ & $\Delta R_{\text {Pressure }}(\%)$ \\
\hline Bare & - & - & - \\
Case 1 & 8.9 & 28.1 & 71.9 \\
Case 2 & 11.9 & 36.8 & 63.2 \\
Case 3 & 13.9 & 42.1 & 57.9 \\
Case 4 & 11.4 & 32.7 & 67.3 \\
Case 5 & 13.4 & 37.2 & 62.8 \\
Case 6 & 16.7 & 44.3 & 55.7 \\
Case 7 & 18.6 & 49.5 & 50.5 \\
Case 8 & 19.8 & 51.2 & 48.8 \\
Case 9 & 20.7 & 52.9 & 47.1 \\
\hline
\end{tabular}

decrease in resistance was $20.7 \mathrm{~N}$ in Case 9. The amount of resistance reduction increased with increasing amount of air injected. In addition, as the amount of injected air increased, there was a greater reduction in frictional resistance. Interestingly, the rate of the decrease in the pressure resistance was as large as the rate of the decrease in shear resistance.

In Case 9, the shear resistance and pressure resistance were 52.9\% and $47.1 \%$, respectively. Previous research considered only the reduction in frictional resistance. On the other hand, both the frictional resistance and pressure resistance decreased when air lubrication was used. When air is injected, an air layer is generated on the bottom of the hull, which alters the resistance state of the ship. Thus, it is necessary to analyze the various changes due to air at these locations.

Fig. 5 shows the distribution of the volume fraction on the bottom of the hull. A larger air flow rate resulted in a larger diffusion angle and air layer thickness. The jetted air goes up on the bottom of the hull to the stern.

Fig. 6 shows the wall shear stress distribution on the hull surface, as seen from the bottom of the hull. The rate of decrease in the frictional resistance was the highest in Case 9, which has the highest air injection flow rate. The result appears similar to the shape of the volume

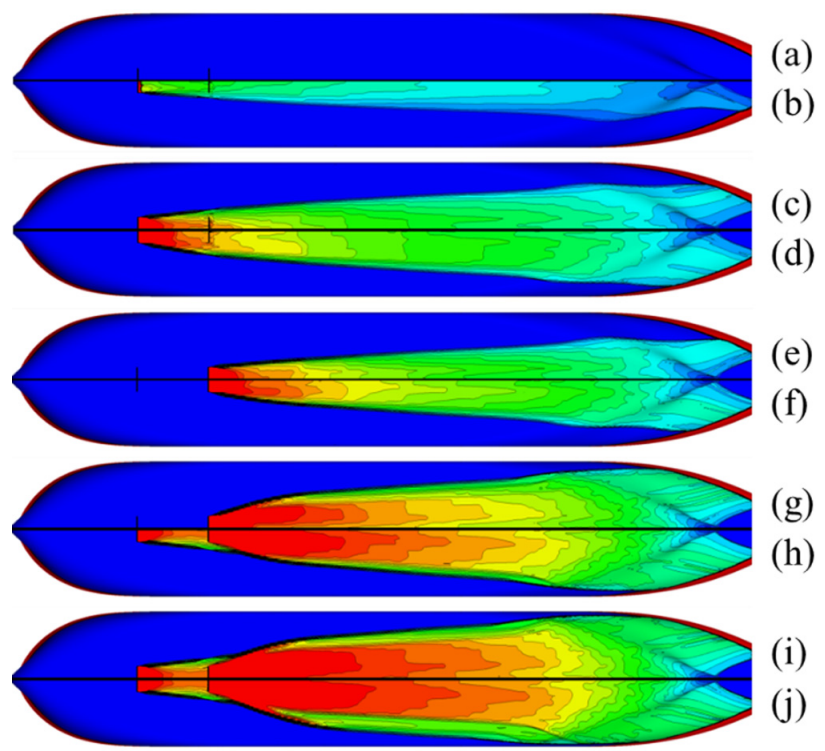

Fig. 5 Volume fraction of air on the hull surface (Bare, Cases 1-9 from top)

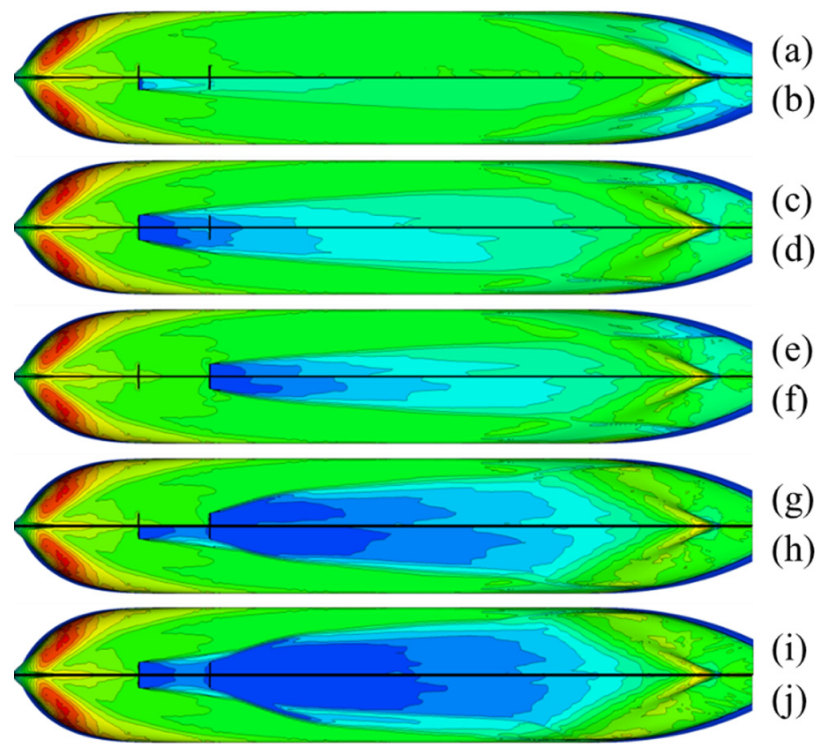

Fig. 6 Wall shear stress on the hull surface (Bare, Cases 1-9 from the top)

fraction on the hull surface.

Fig. 7 shows the distribution of the dynamic pressure on the bottom of the hull. When air is injected, the air affects the distribution of the dynamic pressure at the stern. As the quantity of air increases, a high pressure forms, and the affected area increases.

Numerical analysis of the model ship confirmed that the air layer reduces the frictional resistance through the volume fraction of air on the bottom hull surface. In addition, it changes the pressure resistance, as shown in Figs. 7 and 8. Jang et al. (2014) used a modified method based on ITTC 1957 for the estimation (Method 1). On the other hand, they did not consider the change in pressure resistance. Method 2 is proposed in this study, which considers the decrease in pressure resistance. 


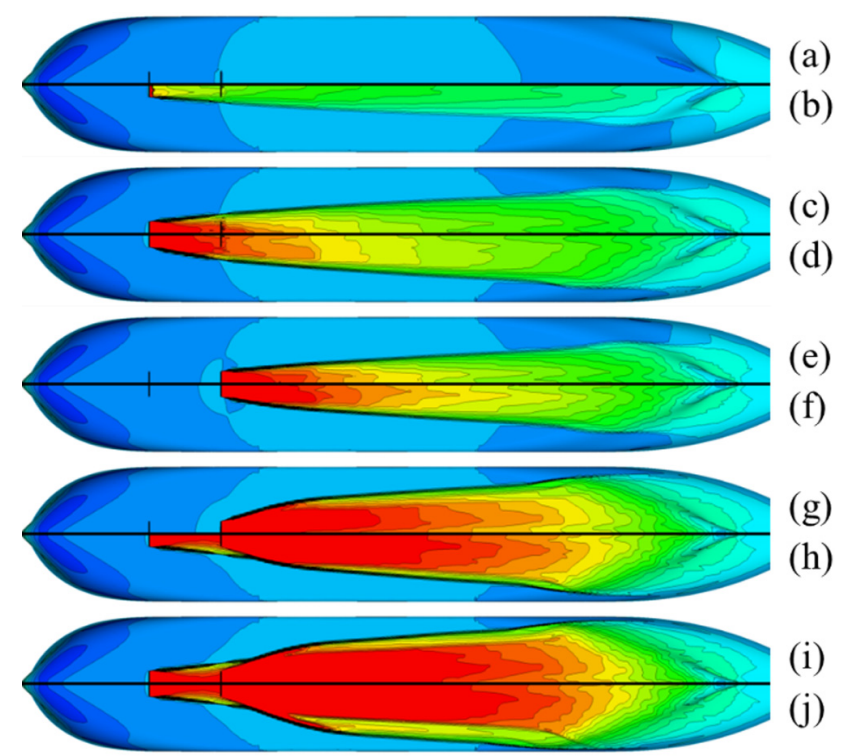

Fig. 7 Dynamic pressure on the hull surface (Bare, Cases 1-9 from the top)

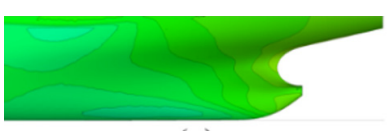

(a)

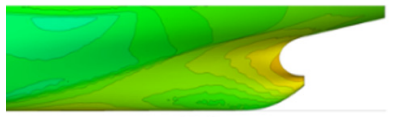

(b)

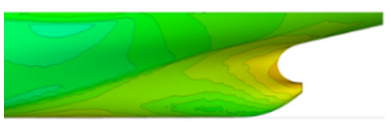

(c)

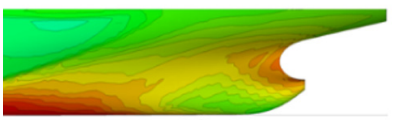

(d)

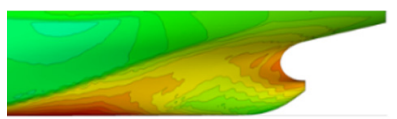

(e)

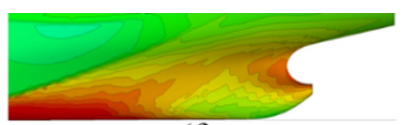

(f)

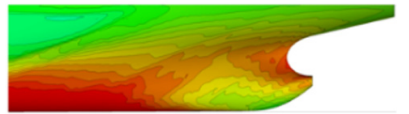

(g)

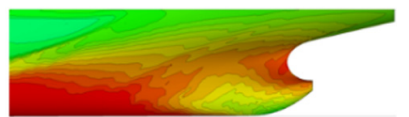

(h)

(i)

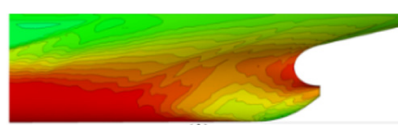

(j)

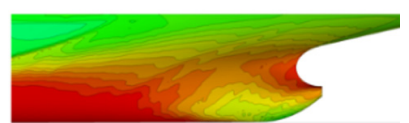

Fig. 8 Dynamic pressure on the stern (Bare, Cases 1-9 from the top and left)

Fig. 9 shows the extrapolation methods used for an air-lubricated ship. In Method $1, C_{T M}$ is divided into $C_{F M}$ and $C_{R M}$, which are the frictional resistance and residual resistance. For $C_{R M}$, it is assumed that the residual resistance coefficient is the same, regardless of whether air is injected. Furthermore, $C_{R M \text {.Air }}$ and $C_{R S \text {.Air }}$ are the same. $C_{F M \text {.Air }}$ can be obtained from the relationship between $C_{T M . A i r}$ and $C_{R M \text {.Air }} . C_{F M . B a r e}$ and $C_{F S \text { Bare }}$ are estimated using the ITTC 1957 method. In the subscript, Bare and Air refer to the case where the air is not injected and when air is injected, respectively. $C_{F S \text {.Air }}$ can be acquired from multiplying $C_{F S \text { Bare }}$ by the ratio of $\mathrm{C}_{\mathrm{FM}}$ obtained in the air and bare conditions of the model ship. As a result, $\mathrm{C}_{\mathrm{TS} \text {.Air }}$ can be estimated as the sum of $C_{F S . A i r}$ and $C_{R S . A i r}$ for a full-scale ship.

\begin{tabular}{c}
\hline Bare: $C_{\text {TM.Bare }}=C_{F M, \text { Bare }}+C_{R M, \text { Bare }}$ \\
\hline$C_{R M . \text { Air }}=C_{R M . \text { Bare }}$ \\
\hline Air: $C_{F M . A i r}=C_{T M . A i r}-C_{R M . A i r}$ \\
\hline$C_{F M . B a r e}, C_{F S . B a r e}=I T T C 1957$ \\
$C_{F S, A i r}=\frac{C_{F M, A i r}}{C_{F M . B a r e}} \times C_{F S . B a r e}$ \\
\hline$C_{R S . A i r}=C_{R M . A i r}$ \\
$C_{T S . A i r}=C_{F S . A i r}+C_{R S . A i r}$ \\
\hline
\end{tabular}

(a) Method 1

\begin{tabular}{|c|}
\hline Bare: $C_{T M . \text { Bare }}=C_{V M, \text { Bare }}+C_{W M, \text { Bare }}$ \\
\hline$C_{V M . \text { Bare }}=C_{T M . \text { Bare }, D B}$ \\
\hline$C_{W M . A i r}=C_{W M . \text { Bare }}=C_{\text {TM.Bare }}-C_{\text {VM.Bare }}$ \\
\hline $\begin{aligned} C_{V M . A i r} & =C_{\text {TM.Air }}-C_{\text {WM.Air }} \\
C_{V S . \text { Bare }} & =(1+k) C_{F S . I T T C 1957}\end{aligned}$ \\
\hline$C_{V S, \text { Air }}=\frac{C_{V M, \text { Air }}}{C_{V M . \text { Bare }}} \times C_{V S . \text { Bare }}$ \\
\hline
\end{tabular}

\begin{tabular}{c}
$C_{\text {WS.Air }}=C_{\text {WM.Air }}$ \\
$C_{\text {TS.Air }}=C_{\text {VS.Air }}+C_{\text {WS.Air }}$ \\
\hline
\end{tabular}

(b) Method 2

Fig. 9 Extrapolation methods for an air-lubricated ship

In Method 2, $C_{T M}$ is divided into the viscous resistance $C_{V M}$ and wave-making resistance $C_{W M}$ to reflect the change in the viscous pressure resistance. The residual resistance of Method 1 is defined as the wave-making resistance in Method 2. $C_{W M}$ Bare is calculated from the relationship between $C_{T M \text {.Bare }}$ and $C_{V M \text {.Bare. }} C_{W M \text {.Air }}$ is assumed to be the same as $C_{W M . B a r e} C_{V M . A i r}$ can be obtained from the relationship between $C_{T M . A i r}$ and $C_{W M \text {.Air }}$ when the air is injected. $C_{V S . B a r e}$ is obtained using the ITTC 1957 method. $C_{V S . A i r}$ is obtained by multiplying $C_{V S \text { Bare }}$ by the relationship with $C_{V M}$ of the model ship when air is injected and not injected. The wave-making resistance coefficient is the same for both the full-scale ship and the model ship. This process is used to derive $C_{T S . A i r}$. The largest difference between Methods 1 and 2 is the scaling of the viscous pressure resistance. In Method 2, the effects of the reduction of pressure resistance by the air lubrication are considered in the extrapolation method to predict the full-scale resistance.

To obtain the viscous resistance component, it is necessary to know the component of the wave-making resistance. Accordingly, doublebody analysis was performed. The following grid conditions were used: $\mathrm{y}+$ was set to 90 , and the number of grids was approximately 
Table 6 Comparison of $\mathrm{C}_{\mathrm{VS}}$ using full-scale analysis

\begin{tabular}{ccc}
\hline Case & $C_{V S}$ & $\Delta C_{V S}$ (based on method 2) \\
\hline Method 2 & 0.00190 & - \\
$y+(300)$ & 0.00205 & 8 \\
$y+(8000)$ & 0.00196 & 3 \\
\hline
\end{tabular}

1.8 million for the model scale.

Cases 3, 6, and 9 were investigated. A double-body analysis was also carried out for a full-scale numerical analysis. Some cases were validated to set $y+$ and Method 2 was extrapolated from the result of the model analysis, as shown in Table 6 . When air was not injected in $y+(8000)$, the error rate was less than $3 \%$ for a full-scale ship. Yang et al. (2010) compared the wakes between the model and the full-scale ship. When the $y+$ value was 8000 in numerical analysis using the RSM, the error was $1.5 \%$ compared to the full-scale ship. Therefore, $y+$ was set to 8000 , and the number of grid elements was approximately 5.6 million. The air flow rate was analyzed numerically by Froude scaling the quantity of injected air from the model ship.

Table 7 lists the reduction rates of $\triangle$ Shear, $\Delta$ Pressure, and $\Delta C_{V}$ for the model ship and full-scale ship based on cases, in which air is not injected from the double-body analysis. There was no difference in $\Delta$ Shear. The overall tendency was similar between the double-body analysis and Method 2. On the other hand, the biggest difference in $\Delta$ Pressure between the model and full-scale ship was $4.9 \%$. Consequently, the estimation of $\Delta C_{V}$ by Method 2 is consistent with the numerical analysis of the model, but there was a slight difference in the full-scale ship.

The difference in $\triangle$ Pressure was attributed to the form factor, which differs between the model and the full-scale ship. The form factor was set to a constant value in Method 2. Therefore, it is believed to result in differences in $\Delta C_{V}$. Fig. 10 shows the volume fraction of the hull surface when using double-body analysis. The branch was stronger at the end of the slit width for the full-scale ship than the model. The overall tendency was similar to that of the model ship.

Table 8 lists the reduction rate of $\Delta C_{T S}$ by air injection when using Methods 1 and 2. Method 1 showed a $2-5 \%$ difference in the numerical analysis results of the model ship; the largest gap was 5.4\%

Table 7 Comparison of the full-scale ship resistance and model ship resistance, $\Delta$ Shear, $\Delta$ Pressure, and $\Delta C_{V}$ using double-body numerical analysis in Method 2

\begin{tabular}{ccccc}
\hline \multirow{2}{*}{ Case } & \multicolumn{3}{c}{ Double-body analysis } & Method 2 \\
\cline { 2 - 5 } & $\begin{array}{c}\Delta \text { Shear } \\
(\%)\end{array}$ & $\begin{array}{c}\Delta \text { Pressure } \\
(\%)\end{array}$ & $\begin{array}{c}\Delta C_{V} \\
(\%)\end{array}$ & $\begin{array}{c}\Delta C_{V} \\
(\%)\end{array}$ \\
\hline Model (Case 3) & 8.3 & 11.1 & 19.4 & 19.0 \\
Full (Case 3) & 10.3 & 13.5 & 23.8 & \\
Model (Case 6) & 10.4 & 12.7 & 23.1 & 22.8 \\
Full (Case 6) & 10.4 & 14.2 & 24.6 & \\
Model (Case 9) & 15.9 & 13.0 & 28.9 & 28.4 \\
Full (Case 9) & 15.9 & 17.9 & 33.8 & \\
\hline
\end{tabular}

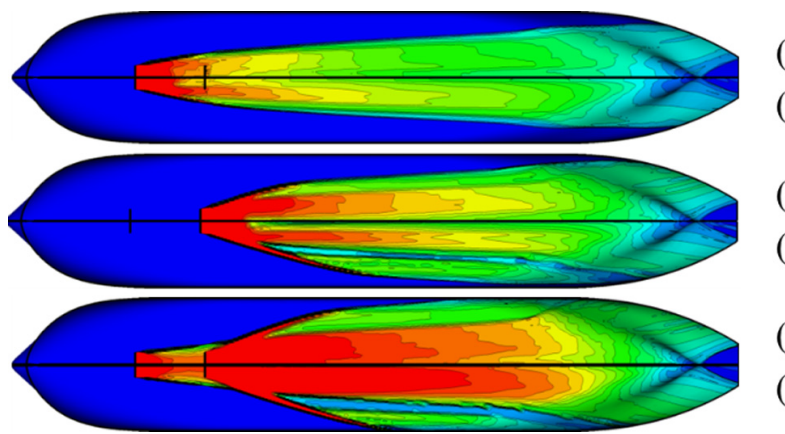

Fig. 10 Volume fraction of the hull surface using double-body analysis. (a), (c), and (e) correspond to Cases 3, 6, and 9 for the model ship, and (b), (d), and (f) are from the full-scale ship.

Table 8 Comparison of the resistance reduction rate of the full-scale ship using Methods 1 and 2

\begin{tabular}{cccc}
\hline Case & $\begin{array}{c}\Delta C_{T S}(\%) \\
(\text { Method 1) }\end{array}$ & $\begin{array}{c}\Delta C_{T S}(\%) \\
(\text { Method 2) }\end{array}$ & $\Delta C_{T M}(\%)$ \\
\hline Bare & - & - & - \\
Case 1 & 8.9 & 10.4 & 11.2 \\
Case 2 & 11.9 & 13.9 & 15.0 \\
Case 3 & 13.9 & 16.3 & 17.5 \\
Case 4 & 11.4 & 13.3 & 14.3 \\
Case 5 & 13.4 & 15.7 & 16.8 \\
Case 6 & 16.7 & 19.5 & 21.0 \\
Case 7 & 18.6 & 21.7 & 23.3 \\
Case 8 & 19.8 & 23.1 & 24.9 \\
Case 9 & 20.7 & 24.2 & 26.1 \\
\hline
\end{tabular}

in Case 9. Method 2, however, showed a 1 - 2\% difference; the largest difference was $1.9 \%$ in Case 9. Method 2 was more accurate than Method 1 when the total resistance reduction rate was compared with that of the model ship. Overall, the variation of the pressure resistance should be considered when estimating the resistance of a ship with an air lubrication system.

\section{Conclusions}

A numerical study was carried out on the effect of air injection on a ship. The mesh was verified, and the reliability of the calculation was confirmed by numerical analysis. The resistance was calculated by double-body analysis, and the estimated resistances of the model and full-scale ship were compared.

Comparisons were made for a bare hull regarding the reduction rate of the total resistance $\left(\Delta R_{T M}\right)$, the ratio of the decrease in shear resistance to the decrease in total resistance ( $\triangle$ Shear), and the ratio of the decrease in pressure resistance to the decrease in total resistance ( $\triangle$ Pressure). A larger decrease in the total resistance was observed when the air injection flow rate increased. The rate of the decrease in pressure resistance was as large as the rate of the decrease in shear 
resistance. Bow trim was generated due to the buoyancy by the air, and the heave increased.

Based on the results, a resistance estimation method was proposed to consider reducing the pressure resistance, and the results were compared with those of the modified ITTC 1957 method. The proposed method was more accurate than the modified method. The result of the model scaling showed less than $1 \%$ error, whereas the result of the full-scale ship shows a slight difference.

Methods 1 and 2 were compared to find the differences between $\triangle$ $C_{T S}$ and $\Delta C_{T M}$. Method 2 was more accurate than Method 1 in estimating the resistance of the full-scale ship from the model ship, and the error rate was less than $2 \%$. The ultimate goal of developing an air lubrication system is to reduce the fuel consumption of a ship by $5 \%$ or more and improve the performance at sea. To achieve this goal, it is necessary to estimate the resistance of the model and full-scale ship accurately when air is injected. Future research will be needed to improve the reliability of the results on a full-scale ship.

\section{Acknowledgments}

This research was funded by a research grant for the development of an air lubrication system to reduce ship fuel consumption by approximately 5\% and verify the performance at sea [10073164], which is supported by the Ministry of Trade, Industry, and Energy.

\section{References}

Bushnell, D.M., \& Hefner, J.N. (1990). Viscous Drag Reduction in Boundary Layers. Proceedings of The American Institute of Aeronautics and Astronautics, Inc., Washington DC, USA.

Ceccio, S.L., Perlin, M., \& Elbing, B.R. (2010). A Cost-Benefit Analysis for Air Layer Drag Reduction. Proceedings of International Conference on Ship Drag Reduction (SMOOTH-
SHIPS), Istanbul, Turkey.

Ceccio, S.L., \& Makiharju, S.A. (2012). Air Lubrication Drag reduction on Great Lakes Ships. Great Lakes Maritime Research Institute, A University of Wisconsin - Superior and University of Minnesota Duluth Consortium.

Jang, J.H., Choi, S.H., Ahn, S.-M., Kim, B.K., \& Seo, J.S. (2014). Experimental Investigation of Frcitonal Resistance Reduction with Air Layer on the Hull Bottom of a Ship. International Journal of Naval Architecture and Ocean Engineering, 6(2), 363-379. https://doi.org/10.2478/ijnaoe-2013-0185

Kim, H.-J., Kim, D.-Y., Shin, H.-W., Kim, S.-H., \& Paik, K.-J. (2017). Numerical Study on the Bifurcation Mechanism of Air Layer on a Flat Plate. Proceedings of International Workshop on Ship and Marine Hydrodynamics, Keelung, Taiwan.

Mäkiharju, S.A., \& Ceccio, S.L. (2018). On Multi-point Gas Injection to form an Air Layer for Frictional Drag Reduction. Ocean Engineering, 147, 206-214. https://doi.org/10.1016/j.oceaneng. 2017.10.041

Mäkiharju, S.A., Lee, I.-H., Filip, G.-P., Maki, K.-J., \& Ceccio, S.L. (2017). The Topology of Gas Jets Injected Beneath a Surface and Subject to Liquid Cross-flow. Journal of Fluid Mechanics, 818, 141-183. https://doi.org/10.1017/jfm.2017.98

Yang, H.U., Kim, B.-N., Yoo, J.H., \& Kim, W.-J. (2010). Wake Comparison between Model and Full Scale Ships using CFD. Journal of the Society of Naval Architects of Korea, 47(2), 150-162. https://doi.org/10.3744/SNAK.2010.47.2.150

\section{Author ORCIDs}

$\begin{array}{ll}\text { Author name } & \text { ORCID } \\ \text { Kim, Dong-Young } & 0000-0002-4353-8682 \\ \text { Ha, Ji-Yeon } & 0000-0002-3644-4450 \\ \text { Paik, Kwang-Jun } & 0000-0003-4657-5806\end{array}$

